\title{
Ciência da informação: temática, histórias e fundamentos
}

Gustavo Henrique Freire

Doutor em Ciência da Informação

Professor. Pesquisadorl

ghafreire@uol.com.br

Trata dos fundamentos históricos e teóricos do campo científico da informação. Parte da hipótese de que as bases da ciência da informaçãa surgem a partir da emergência do paradigma do conhecimento cientíico apoiado na invenção da imprensa que se institucionaliza com a criação das primeiras associações científicas, e sua expansão está ligada ao desenvolvimento da ciência em todos os segmentos da sociedade contemporânea. Discorre sobre as raízes históricas deste campo cientíico desde a utopia planetária de Otlet e La Fontaine, sobre as abordagens social e tecnológica na ciência da informação, os caminhos no presente e as perspectivas no futuro. Defende que o objeto de estudo da ciência da informação, a informação, é um fenômeno que está relacionado a todos os campos do conhecimento científico, moldando-se aos interesses de cada uma delas. Apresenta um modelo das áreas de interesse pertinentes à ciência da informação, bem como suas inter-relações e possibilidades de intervenção na sociedade. Argumenta que, para superar dificuldades conceituais advindas das múltiplas facetas próprias ao seu objeto de estudo, a ciência da informação deve buscar a construção de uma rede conceitual, tecida a partir do olhar das várias disciplinas com as quais este campo científico se relaciona.

Palavras-chave: Ciência da informação; Comunicação científica; História da ciência. 


\section{Introdução}

Neste trabalho, seguimos as pistas de Leroy-Gourham para quem a organização em sociedade é um dos atributos biológicos da espécie humana e a cultura surge entre "o gesto [trabalho] e a palavra" (LEROI GOURHAN, 1987). Indícios dessa abordagem também podem ser encontrados em Morin, para quem a sociedade humana surge como "uma variante e um desenvo/vimento prodigioso do fenômeno social natural" onde a cultura "constitui um sistema generativo de alta complexidade e [assim,] deve ser transmitida, ensinada, aprendida, quer dizer, reproduzida em cada novo indivíduo no seu período de aprendizagem, para poder se autoperpetuar e para perpetuar a alta complexidade social. (MORIN, 1991, p. 49)

Até que a escrita se disseminasse, inúmeras narrativas orais foram produzidas e circularam nas sociedades pré-históricas, estruturando-se a partir dos valores e categorias da visão de mundo dos seus principais grupos sociais e contendo informações relativas ao saber adquirido e organizado em milhares de anos de observação dos fenômenos naturais e humanos. Histórias contadas e recontadas sem que se perdesse a informação original, um conhecimento sobre as origens do mundo, ou do grupo social, ou de uma prática medicinal, ou de uma técnica:

...na narrativa mítica, se ocultam informações que descrevem e explicam fenômenos físicos e humanos, observados, descritos e registrados com a diversidade cultural própria da espécie humana. Certamente, tanto quanto na sociedade contemporânea, essa estrutura intelectual foi capaz de criar novas formas de expressão do conhecimento, de criar possibilidades de transformação nos grupos e nas estruturas sociais. (FREIRE, 200 I , p. I 8)

Se olharmos, na perspectiva das relações entre modo de produção social e conhecimento, podemos identificar na mudança do paradigma da narrativa oral para a escrita, o que Santillana (1970) denomina fenômeno de transmissão de alta cultura, que seria responsável por saltos qualitativos na história da humanidade. Na história recente da civilização ocidental, podemos identificar o salto representado pela criação da atividade científica, apoiado no salto da imprensa inventada por Gutenberg. Nesse processo, as relações entre as forças produtivas e a produção do conhecimento científico se tornaram cada vez mais objetivas e concretas, e o fenômeno da informação adquiriu nova relevância nas trocas econômicas e culturais da sociedade capitalista. $\bigcirc$ presente texto apresenta uma das narrativas possíveis desse processo.

\section{Raízes históricas do conhecimento cientifico}

Desde os primórdios da evolução da humanidade, a informação, no sentido geral de comunicação, esteve presente através da técnica e da linguagem, ou seja, da maneira sobre como fazer determinados objetos, como roupas, armas, armadilhas, mapas, entre outros, e da forma de transmitir o conhecimento sobre esse fazer. Por sua vez, a técnica, 
como a linguagem, é criada em uma determinada cultura, de acordo com as suas necessidades econômicas e sociais, e irá evoluir de acordo com o contexto em que se encontra.

Sabemos que a imprensa surgiu na China, muito antes que Gutenberg movesse sua primeira prensa. Entretanto, é importante destacar que o alfabeto ocidental, com poucas letras, mas uma possibilidade infinita de combinações, foi decisivo para o crescimento desta tecnologia na Europa, mais rapidamente que na China, uma vez que a escrita chinesa é composta de aproximadamente 60.000 ideogramas. Mas o que mudou o curso da história na Europa foi que, ao contrário da China, existiam condições socioeconômicas para que a imprensa se desenvolvesse como mecanismo de disseminação da cultura. Essas condições podem ser descritas como: crescimento, desde o século XII, de universidades, o que demandava a necessidade de se copiar grande quantidade de textos; a criação das primeiras teorias científicas modernas.

A criação da tecnologia de impressão foi muito importante no desenvolvimento das forças produtivas na sociedade, ao facilitar a circulação da mesma informação com um alcance sem precedentes. Inicia-se, então, um processo de comunicação científica, na medida em que a produção de conhecimentos gera, por sua vez, a necessidade de novos conhecimentos. Isso merece ser destacado, uma vez que nesse período foram iniciadas as bases da nossa sociedade atual, que começou a ser construída quando as associações científicas foram criadas e os primeiros periódicos científicos são publicados, dando início à formalização do processo de comunicação científica.

A partir desse período a atividade científica, baseada no método de experimentação e na matemática, estabelece um novo paradigma social e tecnológico. Nesse contexto, desenvolve sua própria forma de expressão e canais de comunicação e são criadas as primeiras associações científicas. Nesse processo histórico, os profissionais de informação vão estar sempre próximos dos cientistas, seja na organização e na armazenagem das informações produzidas, seja na sua comunicação. Assim, emerge uma visão de mundo e um novo sistema de valores, principalmente entre os séculos $X V I$ e $X V I I I$, que são característicos da sociedade moderna. (CAPRA, 1988).

Enquanto substituía antigas concepções do cosmo, o conhecimento científico adquiria valor para as forças produtivas, até que a Revolução Francesa propiciou à burguesia a ascensão ao poder político e ao domínio econômico, ajudando a instituir definitivamente o campo científico como um espaço de produção social material e simbólica. Neste espaço, os periódicos se afirmaram como meios de divulgação do conhecimento entre os cientistas.

Ainda que a introdução do periódico fosse um passo lógico, suscitava implicações notáveis para a comunicação científica. Em particular, significava uma formalização do processo de comunicação [...] $\bigcirc$ que sucedeu no século XVII foi que os canais existentes para a comunicação científica, principalmente a comunicação oral, a correspondência pessoal e os livros foram complementados, ampliados e, em certa medida, substituídos por um novo canal formal constituído por periódicos. (MEADOWS, 1999, p. 7).

Este momento da história foi muito importante para o desenvolvimento das forças produtivas na sociedade ocidental, não somente pela produção de conhecimentos científicos mas, especialmente, por sua sistematização e comunicação. A partir daí, o conhecimento científico tornase elemento cada vez mais presente na estrutura da visão de mundo da sociedade industrial, tornando-se, mediante o processo de reificação, uma 
atividade produtiva em si - ao mesmo tempo em que é uma nova forma de expressão do conhecimento humano.

\section{A utopia planetária de Otlet e la Fontaine}

Abordando as utopias planetárias de uma perspectiva histórica, Mattelart destaca Paul Otlet e Henri La Fontaine como os visionários da universalidade do conhecimento humano, assinalando o paralelismo surpreendente entre suas representações, no início do século $X X$, e as encontradas neste início do Terceiro Milênio. $\bigcirc$ campo privilegiado de ação dos autores, segundo Mattelart, é a documentação e ...Otlet e La Fontaine fazem dele a base de uma nova ciência, criando, em |895, o Instituto Internacional de Bibliografia, com o objetivo de estudar "as questôes concernentes ao Livro e à organização sistemática da Documentação em bases internacionais e universais" (MATTELART, 2002a, p. 233).

autor volta a citar as idéias de Otlet e La Fontaine na História da sociedade da informação, quando os coloca como fundadores de uma "nova ciência da organização sistemática da documentação", iniciativa que, a seu ver, seria "produto de um espírito visionário" (MATTELART, 2002b, p.47). Entretanto, Figueiredo já apontara para a importância do trabalho de Otlet na construção de uma base teórica para uma ciência emergente, e não somente na criação de tecnologias de informação. Segundo a autora,

[ Tratado] de Documentação [...] é, talvez, "a primeira sistemática e moderna discussão dos problemas gerais da organização da informação". O termo documentação é um neologismo, criado por Otlet, para designar o que hoje em dia tendemos a chamar de armazenamento e recuperação da informação. De fato, "não é exagero declarar-se que o tratado foi um dos primeiros textos de Ciência da Informação..." Propõe novos tipos de sistemas mecânicos integrados para o manejo da informação, os quais teriam ainda de ser inventados e transformariam o meio ambiente e as práticas dos pesquisadores. (FIGUEIREDO, 1996, p. I6).

Assim, a utopia de Otlet e La Fontaine sobre o valor e a universalidade da documentação pode ser vista como origem para a ciência da informação, cuja relevância foi vista na missão científica do Instituto Internacional de Bibliografia, de onde teria surgido "a idéia de bibliografia como registro, memória do conhecimento científico, desvinculada dos organismos, como arquivos e bibliotecas, e de acervos"(PINHEIRO, 1997, p. 28). Em nível conceitual, Otlet expande o conceito de documento, alegando que a documentação consiste em toda a gama de produtos de informação que surgem e se expandem com a revolução industrial: artigos e relatórios científicos e técnicos, desenhos industriais, patentes, protótipos, cartões-postais, fotografias: tudo o que não era considerado material de biblioteca. (PEREIRA, 2000, p. VIII).

Para ele, tornava-se necessário ordenar essa documentação de modo a dar uma resposta ao que lhe parecia o problema central de toda e qualquer sociedade, qual seja, como proceder para que o conhecimento registrado estivesse disponível para quem dele tivesse necessidade. Otlet trabalhava 
nesse sentido porque acreditava que a informaç̧ão, uma vez recuperada, seria capaz de operar comunicação intelectual, mudança social e paz mundial, esperando que o acesso à informaçãa viesse a formar uma opinião pública internacional e democrática, recomendando, para a preparação dessa opinião, uma organização mundial de informação.

Mas, o que torna paradigmático o trabalho de Otlet e la Fontaine não é somente sua percepção da nova relevância do antigo fenômeno da informação, como resumiram Wersig e Neveling ( 1975). O principal é que, no processo de criação dos instrumentos necessários para sua organização, armazenagem e recuperação, Otlet e la Fontaine centraram seus esforços no conteúdo dos documentos, ou seja, na informação em si, e isto foi realmente inovador pois até então nunca havia sido feito.

Assim, esse novo paradigma nasce da atenção dada ao conteúdo (informação, conhecimento registrado) dos documentos, mais do que aos próprios documentos, ao tempo que estabelece uma certa fronteira entre as bibliotecas anteriores e os centros de documentação, onde a resposta à procura de informações e documentos, por temas e outros novos critérios, torna-se possível e amplia-se de forma espetacular. (ROBREDO, 2003, p. 44).

Este novo paradigma informacional deslocou o foco de autores e coleções para o conteúdo dos documentos, para a informação em si, desde a produção do conhecimento cientíico até sua representação [re-significação], organização e distribuição pelos canais formais de comunicação científica. Neste sentido, o usuário começa a se deslocar da periferia para o centro do processo de comunicação da informação, e a informação começa a se constituir como campo de atividade científica.

\section{0 campo da ciência da informação}

Como visto, é inegável que o fenômeno da informação foi se tornando mais presente em nossas vidas, sua área de ação e atuação foi crescendo cada vez mais, até sua identificação com a sociedade contemporânea qualificada como sociedade da informação. Nesse contexto, a característica marcante da atual sociedade não seria apenas a apropriação da informação e do conhecimento pela sociedade, mas a transformação de ambos em forças produtivas.

É nesse sentido que entendemos a emergência das atividades de informação científica como um fenômeno de alta cultura, em que as condições objetivas de produção econômica e cultural da sociedade concretizaram a possibilidade antevista por Otlet. Esse processo ganha impulso durante a Il Guerra Mundial. Nesse período, o mundo passava por um momento de grandes conflitos e os chamados países aliados notadamente os EUA, URSS e Grã-Bretanha, empregaram um grande número de pessoas que passaram a trabalhar em processos de coleta, seleção, processamento e disseminação de informações que fossem relevantes para o esforço de ganhar a guerra.

Encontramos as raízes européias da ciência da informação no Instituto Internacional de Bibliografia, que veio a transformar-se em Federação Internacional de Documentação - FID -, e nos Estados Unidos, onde os indícios, também antigos, se concretizam em 1937, com a criação do American Documentation Institute - ADI -, motivado pelos novos métodos de reprodução de documentos, destacando-se a microfilmagem de documentos. Outros indícios de que a atividade de informação científica tornava-se socialmente 
relevante são a publicação do Journal of Documentation, lançado na Grã Bretanha (ainda em circulação), e do artigo As we may think, do americano Vannevar Bush, ambos em 1945; a Conferência de Informação Científica da Royal Society, realizada em Londres, com quase 500 participantes, em 1948; a publicação do American Documentation, nos Estados Unidos, e do Nachrichten für Dokumentation, na Alemanha, ambos em 1950 e até hoje relevantes periódicos da área. Na URSS, o principal indício é a criação, em 1952, do VINITI - Vserossiisky Institut Nauchnoi i Tekhnicheskoi Informatsii (All-Union Institute for Scientific and Technical Information), vinculado à Academia de Ciências da Rússia, com a missão de prover informação para cientistas e especialistas nas ciências técnicas e naturais.

Considera-se que o registro oficial da denominação ciência da informação data do início da década de 1960, a partir de eventos promovidos pelo Georgia Institute of Technology, nos Estados Unidos, do qual participaram também cientistas, escritores e filósofos estrangeiros e onde foi discutida a criação de novas tecnologias de informação, conseqüência natural do crescimento da produção científica e que redundara na multiplicação dos periódicos científicos. Apesar da ênfase na educação e treinamento profissionalizantes, a realização de debates teóricos permitiu que se chegasse a uma primeira definição do que seria a ciência da informação e mostra a percepção da área pelos americanos.

É Foskett quem nos lembra, entretanto, que as atividades ligadas à produção e gerenciamento da informação científica e tecnológica já tinham uma longa tradição na antiga União Soviética e nos países da Europa Central, onde centros nacionais de informação, como o VINITI, serviram de modelo (inclusive para os EUA) na organização de informação. Lembra também que, em 1967, o diretor do VINITI, professor Mikhailov, havia circulado um memorando entre pesquisadores e trabalhadores da informação com vistas à produção de um documento que trataria de pesquisa teórica sobre informação e seria apresentado na Conferência da FID programada para realizar-se em 1968 em Moscou, mas que não veio a acontecer. Inaugurando a série de publicações do Comitê de Estudos FID/Research Information, os trabalhos encaminhados à conferência foram reunidos e publicados pelo VINITI, em parceria com a FID, em 1969, no documento FID 435 (Research on Theoretical Basis of Information). Nele, os russos apresentam o escopo e o método da Informatika, cujo principal objeto de estudo é o processo de informação científica em toda a sua complexidade. A sua principal tarefa consiste em aumentar a eficiência da comunicação entre cientistas e especialista. (MIKHAILOV, 1969, p. I2).

É importante ressaltar que no documento FID 435, apesar do consenso sobre o valor das técnicas para o desenvolvimento do novo campo científico, a dimensão social é apontada como fundamental para a questão informacional. Para Foskett, aceitando-se ou não o termo informática como designação para o novo campo científico, o reconhecimento de uma disciplina nova e emergente deve nos salvar de uma estreita e introspectiva concentração de técnicas e fins, e nos esclarecer, de um lado, sobre a diferença entre uma simples tecnologia de pontos moveis daqui para lá, e de outro, sobre a atividade multifacetada que ocorre num contexto social significativo. (FOSKETT, 1980, p. 16).

Em 1975, o Comitê de Estudos FID/RI, em parceria com o VINITI, publica o documento FID 530 (Problemas da Ciência da Informação), trazendo um novo artigo de Mikhailov e colaboradores sobre o campo científico da informação: 
Deixaremos para os futuros historiadores da informática estudar de maneira mais completa a evolução que o termo ciência da Informação tem sofrido [e] visto que o termo anglo-americano pode levar alguém a interpretá-lo num amplo sentido [...] achamos necessário enfatizar que a palavra informação aqui significa apenas informação científica. (MIKHAILOV, 1980 p.7I-72).

Dantas assinala que a abordagem dos cientistas soviéticos, liderados por Mikhailov, aponta para as possibilidades e a legitimidade de um estudo dialético da informação, contribuindo para dotar a ciência da informação de uma perspectiva crítica sobre suas próprias atividades e interesses. (DANTAS, 1994). Entretanto, apesar de sua visão social, Mikhailov e colaboradores restringiam a prática da ciência da informação ao campo das atividades científicas e técnicas, excluindo da sua perspectiva a explicitação de outros grupos sociais, como assinala Roberts. Em artigo publicado em 1976, ele reconhece a inegável autoridade de Mikhailov no que diz respeito às bases teóricas da ciência da informação, mas critica sua visão restrita sobre os limites de seu campo de atuação na sociedade. E se mostra admirado de que os russos, partindo de uma premissa tão ampla quanto a de necessidades sociais, tenham restringido as atividades desse campo científico ao atendimento de uma comunidade que já é privilegiada em se tratando de informação, sendo-lhe difícil entender "porque os problemas de informação de outros grupos sociais não são merecedores do mesmo nível de interesse" (ROBERTS, 1976, p. 250). A questão nos leva, assim, da discussão sobre a emergência e o escopo da ciência da informação ao estudo dos problemas da informação e, nestes, aos diversos construtos sobre os quais foram estruturadas as visões de informação neste campo científico.

Saracevic, por exemplo, aponta três características gerais que constituem a ciência da informação: interdisciplinaridade, ligação inexorável com a tecnologia de informação e por último uma participação ativa e deliberada na evolução da sociedade da informação. (SARACEVIC, 1996). Com relação à abordagem interdisciplinar, isto tem levado a estudos epistemológicos que buscam mapear as relações entre a ciência da informação e outras áreas científicas. Estas relações são dinâmicas e podem ser mais fortes em um determinado tempo e espaço com algumas áreas científicas, enquanto com muitas outras serão fracas ou ainda irão surgir pontos de interseção. Isto não quer dizer que não existam as áreas seminais, como a biblioteconomia, a computação, a comunicação, a psicologia e lingüística. (FOSKETT, 1980).

Quanto à segunda característica, ligação com a tecnologia de informação, pensamos que a relação entre a ciência da informação e a tecnologia para sua produção e comunicação ocorre muito antes da chamada revolução tecnológica da informação, que alguns historiadores situam a partir da II Guerra Mundial. É nesse sentido que preferimos pensar em tecnologia da informação como uma tecnologia intelectual, considerada por Lévy como sendo tanto as formas de expressão simbólica (que, por exemplo, evoluíram das narrativas míticas às equações quânticas) quanto as tecnologias de informação em si mesmas (por exesemplo, a escrita em tabuinhas de barro, as iluminuras medievais, a imprensa e os computadores). [Essas tecnologias] situam-se fora dos sujeitos cognitivos, como este computador sobre minha mesa ou este livro em suas mãos. Mas elas também estão entre os sujeitos 
como códigos compartilhados, textos que circulam, programas que copiamos, imagens que imprimimos e transmitimos por via hertziana. As tecnologias intelectuais estão ainda nos sujeitos, através da imaginação e da aprendizagem. (LÉVY, 1993, p. 47). Grifo nosso.

Por fim, com a sugestão de uma participação "ativa e deliberada na evolução da sociedade da informação", Saracevic resgata a idéia de uma responsabilidade socia/ para a ciência da informação, proposta por Wersig e Nevelingem. (1975, I2).

Essas três características são importantes por representarem, de certa forma, um consenso entre pesquisadores da área da ciência da informação. Para ele, o "problema era (e, basicamente, ainda é) a tarefa massiva de tornar mais acessível um acervo crescente de conhecimento", o que Vannevar Bush havia identificado como explosão informacional: "o irreprimivel crescimento exponencial da informação e de seus registros, particularmente em ciência e tecnologia." (SARACEVIC, 1996, p. 42). Assim, se existe a pista de um fio condutor para tratar de uma ciência cujo objeto de estudo está presente em todas as atividades humanas, a informação, este pode ser procurado na perspectiva de uma visão social que se faz presente desde as origens do campo científico da informação.

\section{0 passado no presente}

Entendemos que a perspectiva científica da informação foi uma inovação no campo da produção e comunicação do conhecimento científico, pois trouxe a possibilidade de toda uma criação de tecnologias de informação que se desenvolveram e continuam a evoluir até os nossos dias. Se num primeiro momento a ênfase era no armazenamento da informação e sua disseminação para grupos específicos, como, por exemplo, os cientistas, hoje, o desafio passa a ser a distribuição de informações que seriam, ou não, úteis para a sociedade em geral.

Seguindo as pistas de uma visão social da informação, Freire (2004) pressupõe algumas condições básicas para a sua existência, tais como:

- Ambiente social - Contexto que possibilita a comunicação de informação. Esse ambiente se caracteriza sempre pela existência de uma possibilidade de comunicação. Ele decorre do impulso primeiro, arquétipico que nos levou como espécie à necessidade de materializar o pensamento em uma mensagem dirigida a um semelhante, um movimento primordial de transmissão da informação;

- Agentes - No processo de comunicação, os agentes são o emissor, aquele que produz a informação, e o receptor, o que recebe a informação. Os agentes emissores são responsáveis pela existência dos estoques de informação, em um processo contínuo em que as funções produção e transferência se alternam, ou seja, o receptor de hoje poderá ser um produtor da informação amanhã;

- Canais - Os canais estão relacionados aos meios por onde as informações circulam. Os agentes produtores de informação escolhem os 
canais mais adequados para circulação da sua informação, que podem utilizar-se de meios impressos, como jornais, revistas, periódicos científicos, livros, além de rádio, televisão, Internet, congressos, feiras e outros tipos de eventos científicos e comerciais. (FREIRE, 2004, p. 20-21).

Essas seriam as condições que tornam possível o processo de comunicação entre emissor e receptor da informação se estabelecer. $\bigcirc$ ambiente humano é fundamental, sem ele não seria possível a existência e atuação dos agentes de informação. Mas informação é sempre um conceito difícil de se traduzir em construtos teóricos, pois não é um fenômeno estático, antes, pelo contrário. Está presente em todas as atividades humanas, inclusive na própria qualificação da sociedade contemporânea, que entre outros recebe o nome de sociedade da informação. No presente texto, argumentamos, em consonância com outros autores do campo da ciência da informação, que a informação sempre foi relevante para o desenvolvimento da sociedade humana, mas que em nossos dias ganhou um novo destaque. E não somente pelo seu alto grau de importância e penetrabilidade em todos os setores da sociedade, especialmente no campo científico, mas como necessidade presente em todos os aspectos da atividade humana.

Neste sentido, uma das grandes preocupações dos pesquisadores de nossa área pode ser resumida em uma questão: qual é a informação que interessa à ciência da informação? Ou melhor, qual é o escopo da ciência da informação? Parece-nos natural que estas perguntas estejam sempre como pano de fundo nas questões de informação, em nosso campo de atividade, como observamos em seção anterior. Isto aparece, de certa forma, em tentativas de definir informação com uma visão operacional (para resolver a questão da explosão informacional, por exemplo, ou em abordagens voltadas para questões de comunicação da informação e, ainda, em estudos da cognição.

Assim, com o objetivo de aumentar a compreensão de seu objeto de estudo e do seu campo de domínio, historicamente os autores do campo da ciência da informação vêm se utilizando de diversos esquemas conceituais e modelos teóricos para explicar esta área do conhecimento científico. Saracevic, por exemplo, em artigo sobre a origem, evolução e relações da ciência da informação, tece uma rede conceitual a partir de Borko, mostrando a evolução dos conceitos até chegar ao que ele chama de enfoque contemporâneo, a partir do qual propõe seu próprio conceito deste campo científico, o qual se dedica às questões científicas e à prática profissional, com o propósito de resolver problemas relacionados com o processo de comunicação humana da informação e de seus registros nos mais variados contextos de uso e de necessidades, sem esquecer a importância das novas tecnologias de informação. (SARACEVIC, 1996).

Uma outra visão para abordar o fenômeno da informação, que se aproxima de conceitos recentes sobre a própria atuação da ciência da informação sobre a sociedade, é a de González de Gómez (2004), que apresenta a informação como um conceito relacional, que interage com contextos informacionais (regimes de informação) diversos, o que seria próprio da sociedade contemporânea. Ela sugere um novo olhar social sobre a informação, que tem como perspectiva as tecnologias digitais de comunicação da informação, segundo a autora,

Em lugar de o social oferecer conceitos esclarecedores do que 
seja a informação, agora a informação e a comunicação, sob o embalo e propulsão das novas tecnologias de comunicação e informação - NTICs -, são necessárias ao esclarecimento e compreensão das novas configurações sociais. (GONZÁLEZ DE GÓMEZ, 2002, p. 26).

Estes exemplos mostram as várias visões, ou melhor, as variadas maneiras de abordagem da informação e da ciência da informação. Nesse sentido, organizamos um quadro que resume nosso olhar sobre a questão através de categorias que agregam áreas de estudos informacionais neste campo científico. É importante destacar que, definidas especificamente para o presente trabalho, a proposição destas categorias não se pretende definitiva, sendo apenas uma das maneiras possíveis de abordar as áreas de estudo e aplicação na ciência da informação. É necessário, também, esclarecer que imaginamos que todas estas categorias estão relacionadas entre si, em um processo dinâmico de interseção, às vezes maior ou menor, umas com outras.

Assim, são categorias dinâmicas e não-hierarquizadas: talvez uma determinada época exija maior foco e atividade em alguma categoria específica, mas pensamos que todas são importantes para o campo científico da informação.

As categorias nas quais pensamos reunir os vários olhares da ciência da informação sobre seu mutante objeto de estudo são:

Recuperação da informação

Representação da informação (linguagens documentárias e linguagem natural), tecnologias de processamento de informação, serviços de informação (bibliotecas, centros de informação)

\section{Comunicação da informação}

Tecnologias de informação e comunicação (especialmente as digitais), produção e recepção da informação, canais de comunicação (formais e informais), uso da informação

\section{Estudos da cognição}

Estudos de usuários, aplicações de inteligência artificial, estudos ligados à aprendizagem em meio virtual (treinamento, capacitação).

É possível observar, em cada área citada acima, um olhar específico sobre a informação, seja para o seu tratamento, para a sua compreensão como processo de comunicação, ou para entender os fatores que levam à sua assimilação e transformação em conhecimento. $\bigcirc$ importante é perceber que todas se relacionam entre si, que não são categorias estanques (a própria natureza dinâmica da informação assim o exige), que sempre haverá pontos de interseção. Como exemplo das relações entre categorias, vamos trabalhar com as tecnologias digitais de informaçãa e comunicação, uma das áreas de atividade da categoria comunicação da informação que perpassa as demais categorias do nosso esquema. Embora sejam adaptadas e transformadas quando em relação com cada categoria, essas tecnologias mantêm, em todas elas, a sua função de transportar a informação de uma fonte para um dado grupo de usuários, na sociedade.

$\mathrm{Na}$ comunicação da informação modificam a própria forma de produzir e comunicar informações: na Internet já é difícil fazer a distinção entre canais formais e informais, conceitos que estão sendo revistos 
pois um e-mail pode ser abordado como um misto dos dois canais, já que a informação está registrada. As tecnologias também têm grande impacto na comunicação científica em si, pois a circulação de pré-prints em meio eletrônico tem aumentado, principalmente nas áreas em que a produção científica exige que o conhecimento se torne público o mais rapidamente possível.

Na recuperação da informação, essas tecnologias são utilizadas para criação de linguagens de controle para recuperação da informação que fiquem mais próximas das linguagens naturais, para oferecer serviços de informação à distância e implementar o compartilhamento e a troca de informação entre pesquisadores.

Com relação aos estudos da cognição, é importante ressaltar que, no contexto das tecnologias digitais de informação e comunicação, os usuários passam a ter um papel ativo na busca de informação, uma vez que os meios de acesso estão ao seu alcance (bases de dados, bibliotecas virtuais, páginas pessoais e outros agregados de informação). Este aspecto tecnológico abre inúmeras possibilidades para construção de estoques de informação com a participação ativa de usuários, ao mesmo tempo em que organiza a formação das comunidades de interesse e de prática, no campo científico. $\bigcirc$ estudo dessas comunidades, e de outras que não se situam no campo científico, se configura como um novo espaço para a abordagem cognitivista na ciência da informação, não mais baseado nos processos mentais do indivíduo (como em Belkin, por exemplo), mas levando em consideração o contexto social no qual o processo de informação ocorre (HJORLAND e ALBRECHTSEN, 1995).

Os conceitos que se relacionam de forma mais próxima com área da recuperação da informação são aqueles que abordam a informação como um objeto passível de ser organizado e armazenado em algum suporte, principalmente digital. Por sua vez, outros conceitos de informação situam-se na categoria comunicação da informação, como o proposto por Wersig em 1993, por exemplo. Para ele, "informação é conhecimento em ação [...] como algo que serve de apoio a uma ação específica em uma situação específica", na premissa de que todo comportamento humano necessita de algum tipo de conhecimento (WERSIG, 1993, p. 233). Nos estudos cognitivos, os conceitos de informação estão relacionados com a aplicação de um determinado conhecimento através de uma ação de comunicação realizada em determinado contexto social, institucional ou individual. Esta abordagem revela a importância da informação no cotidiano da sociedade contemporânea, em especial nas atividades de educação e comunicação.

Nosso modelo teve o propósito de mostrar as múltiplas possibilidades de relações que existem entre as categorias de informação e sua contextualização, tanto no campo científico quanto na sociedade em geral. Como em qualquer campo científico, também na ciência da informação será possível identificar uma rede conceitual que relaciona os vários construtos de informação entre si e as próprias noções sobre o campo científico, a qual também pode ser vista a partir das categorias que resumimos acima. Nesse sentido, sejam centenas as definições de informação nos vários campos da atividade científica, cada um deles irá defini-la de acordo com o seu interesse específico, cabendo aos pesquisadores da ciência da informação o desafio maior de determinar a 
própria forma. A própria busca de um construto de informação nos impulsiona e nos mantém, como no mito do Graal

Nas sociedades pós-modernas, os indivíduos não entram em contato com a realidade através da sua práxis, mas pela informação veiculada pelos meios de comunicação de massa ou armazenada nos bancos de dados. A informação mediatiza os processos de apreensão da realidade, e as próprias relações sociais (MARTELETO, 1987, p. 177).

Nesse contexto, um dos objetivos da ciência da informação seria contribuir para a informação se tornar, cada vez mais, um elemento de inclusão social, trazendo desenvolvimento para as pessoas e nações. Dessa forma, haveria uma responsabilidade socia/como fundamento para a ciência da informação definindo sua atuação na sociedade. Quando cientistas e profissionais da informação organizam textos ou documentos para atender a necessidade de um determinado setor da sociedade, deveriam fazê-lo acreditando que essas informações serão úteis para seus usuários potenciais e que delas resultarão benefícios para a sociedade.

Dessa forma, podemos imaginar que a ciência da informação deva continuar sua epopéia para descobrir novas formas de pensar e agir de maneira ativa nos diversos processos de comunicação na sociedade. Sociedade onde existem, cada vez mais, pessoas que precisam ter acesso à informação, nas mais diversas fontes e através dos mais variados canais.

$\bigcirc$ que, em se tratando das atividades de informação, pode significar a busca de uma tecnologia entre o real e o virtual, valorizando o que de mais importante existe no processo de comunicação da informação, os seres humanos, principal personagem desta narrativa.

\section{Information Science: themes, histories and foundations}

This article handles the historical and theoretical foundations of the scientific field of information. It starts from the hypothesis that the Information Science basis were generated from the emergency of the scientific knowledge paradigm - sustained by the invention of the press - that was established with the first scientific associations, and that the Information Science expansion is linked to the science expansion throughout all the segments of the contemporary society. The article approaches the historical roots of this scientific field from the planetary utopia by Otlet and La Fontaine, the social and technological visions in the Information Science, the present ways and future perspectives. The author defends that the Information Science study subject - information is a phenomenon related to the scientific knowledge fields as a whole, fitting their interests. The article presents a model of the Information Science interest areas and their interrelationship and possibilities of intervention in society. Finally, the author defends that, to overcome conceptual difficulties originated by the multiple faces inherent to the study object, the Information Science should build a conceptual network, woven from within the view of the various disciplines which this scientific area is related to.

Key-words: Information Science; Scientific communication; Science history 


\section{Referências}

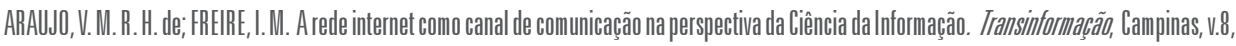
n.2, p. $45-56,1996$.

BARRETO, A. de A. A questão da informação. São Paulo eml Perspectiva. São Paulo, v. 8, n.4, 1994.

BELKIII, N.J. Cognitive models and information transfer. Socia/Science/nformation Studies, n. 4, 1984.

Some soviet concepts of Information for Information Science. Journalof the American Society for Information Science, p. 56-64, 1975.

BORKO, H. Information science: what is it? American Docummentation, v. 19, n.1, 1968.

BOURDIEU, P. O campo cientifico. In: ORIIZ, R. (Org.). Sociologia. 2.ed. São Paulo: Ática, 1994.

BROOKES, B. C. Lenin: the founder of informatics. Journa/ of Information Science, v.8, p. 221-231, 1984. Brief Communication.

BURKE, P. Uma história social do conhecimento: de Gutenherg a Diderot. Rio de Janeiro: Zahar, 2003.

BUSH, V. As we may think. In: Evolution of an information society. London: ASLLB, 1987.

CAPRA, F. Oponto de mutą̧ão. São Paulo: Cultrix, 1980.

CASTELLS, II. A sociedade emr rede. São Paulo: Paz e Terra, 1999.

DANTAS, MI. Irabal/ho com informaz̧ão.investigação inicial para um estudo na teoria do valor. 1994. Dissertação (Mestrado em Ciência da Informação). UFRJ/ Escola de Comunicação, 1994.

DAY, R. Paul Otlet's s Book and the writing of social space. Journal of the American Society for Information Science, v. 48, n. 4, p. 310-317, 1997.

FARRADAME, J. The nature of information. Journalof Information Science, v.1, 1979.

FIGUEIREDO, N I . Paul Otlet e o centenário da FID. In: ORGAAMIZCÇÃO do conhecimento e sistemas de classificação. Brasília: IBICT, 1996.

FOSKETI, D.J. Informática. In: GOMES, H.E. (Org.). Ciênncia da Informação ou informática? Rio de Janeiro: Calunnga, 1980.

FREIRE, G. H. de A. Comunicacąão da informacão em redes virtuais de aprendizagem. 2004. Tese (Doutorado em Ciência da Informação). Convênio CWPף IBICT-UFRJ/ECO,2004.

FreIRE, I. M. A Aresponsabilidade socialda Ciênncia da Informação e/ou o olhar da consciência possive/ sobre o cammo cientificic. 2001. Tese (Doutorado em Ciência da Informação)-Convênio CWPq//BICT -UFRJ/ECO,2001.

FREIRE, I. M.; ARAUJO, V. M. R. H. de. A responsabilidade social da Ciência da Informação. Iransinformaģão, Campinas, v.11, n.1, p.7-15, 1999.

GARCIA, J.C. R. Conferências do Geórgia Institute of Technology e a Ciência da Informação: "de volta para o futuro". Inf. \& Soc.. Estudos, v. 12, n. 1, 2002. Disponivel em: www.informaçãoesociedade.uffph.br.

GOLDMANIN, L. Ciênncias humanas e filosofia; o que é a sociologia? 7.ed. Rio de Janeiro: DIFEL,1979.

GONZÁLEZ DE GÓMEZ, M. II. Dos estudos sociais da informação aos estudos do social desde o ponto de vista da informação. In: AQUnWO, M. de A. (Org.). 0 cammpo da Ciênncia da Informação. João Pessoa: UFPB, 2002.

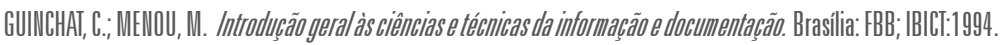

HJQRIAMD, B:;ALBECHTSEN, H. Toward a new horizon in information science: domain-analysis. Journalof the American Sacietyffor Information Science, v. 46, n. 6, 1995 .

LA FONTAIME, H., OTLEI, P. La vie internacionale etl'efffort pour sa organization. La Vie /nternacionale, v. 1, n. 1, 1912.

LEROI-GOURHAN, A. Ogesto e apalaura: técnica e linguagem. Lisboa: Ed. 70, 1987. 
LÉVY, P. As tecnologilas da inteligêneia. 0 futuro do pensamento na era da informática. Rio de Janeiro: 34,1993.

MARTELETO, R.M. Informação: elemento regulador dos sistemas, fator de mudança social ou fenômeno pós-moderno? Ciênciada Informaçãa, v.16 n.2, p.16980, jul./dez. 1987.

MATTELARI, A. História da uttopia planetária:da cidade profética à sociedade global. Porto Alegre: Ed. Sulina, 2002 (a). História da socieddade da informacãa. São Paulo: Ed. Loyola, 2002 (b).

MCGARRY, K. O contexto dinâmico da informaçãa: uma análise introdutória. Brasilia: Briquet de Lemos/Livos, 1999.

MEADOWS, A.J. A comunicação científica. Brasilia: Briquet de Lemos/liuros, 1999.

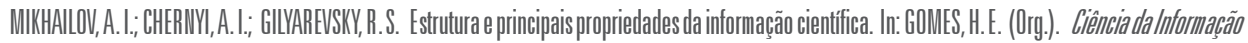
ou Informática? Rio de Janeiro: Calunga, 1980.

Informatics: its scope and methods. In: FID. On theoreticalproblemlis of Informatics. Moscow: FID/RI, VIIIIII, 1969. (FID 435).

Informatic, a new name for theory of scientific information. Nauko-Tekhnicheskayalnformatsiva, n. 12,1966.

MORIII, E. Oparadigmma perdido.a natureza humana. 5.ed. Lisboa: Europa-América, 1991.

PEREIRA, M. N. F. Prefácio. In: PERElRA, M. II. F.: PINHEIRO, L. V. R. O sonho de Ottet: aventura em tecnologia da informação e comunicação. Braślia: IBICT, 2000.

PINHElRO, L.V. R. A Ciềncia da Informação entre sombra e luz: domininio epistemológico e cammpo interdisciplinar. 1997. Tese (Doutorado em Comunicação e Cultura)-UFRJ/Escola de Comunicação, 1997.

ROBERTS, II. Social considerations towards a definition of information science. Journalof Documnentation, v. 32, n. 4, 1976.

ROBREDO, J. Da Ciềncia da Informag̨ão revisitada:aos sistemas humanos de informação. Braślia: Thesaurus; SSRRR Informações, 2003.

SANTILLANA, G. di. O historiador e a teoria da informação. In: O conceito de informação na ciênncia contemlmporânea. Rio de Janeiro: Paz e Terra, 1970.

SARACEVIC, I. Ciência da Informação: origem, evolução e relaçōes. Perspectivas eml Liềncia da Informacãão, v. 1, n.1, p. 41-62, jan.jun. 1996.

.A review of an a framework for the thinking on the notion in Information Science. Journal of the American Society for Information Science, p. 321. 343, Nov.Dec., 1975.

SHERA, J. H.: CLEVELAND, D.B. History and foundations of Information Science. Annua/Review of Information Science and Iechnology, v. 12, p.249-275, 1977.

TAYLOR, R. S. Professional aspects of information science and technology. Annua/Review of Information Science and Technology, v. 1, 1966.

WERSIG, G. Information Science: The study of postmodern knowledge usage. Information Processing and Management, v. 29, n. 2, p.229-239, 1993.

WERSIG, G., MEVELLING, U. The phenomena of interest to information science. The Information Scientist. v. 9, n. 4, 1975. 